\title{
Uranium Oxide as a Highly Reflective Coating from 100-400 eV
}

\author{
Richard L. Sandberg
}

rudyskaboy@yahoo.com

David D. Allred

allred@byu.edu

Luke J. Bissell

Jed E. Johnson

R. Steven Turley

Follow this and additional works at: https://scholarsarchive.byu.edu/facpub

Part of the Astrophysics and Astronomy Commons, and the Physics Commons

\section{Original Publication Citation}

Richard L. Sandberg, David D. Allred, Luke J. Bissell, Jed E. Johnson, R. Steven Turley, "Uranium Oxide as a Highly Reflective Coating from 1-4 eV," in Synchrotron Radiation Instrumentation: Eighth International Conference on Synchrotron Radiation Instrumentation, San Francisco, California, 25-29 August 23, AIP presentation proceedings, ISSN: 94-243X v. 75, edited by Tony Warwick, et al. (American Institute of Physics, Melville, N.Y., 24) pp. 796-799.

[http://proceedings.aip.org/resource/2/apcpcs/75/1/796_1][http://dx.doi.org/1.163/ 1.1757916].

\section{BYU ScholarsArchive Citation}

Sandberg, Richard L.; Allred, David D.; Bissell, Luke J.; Johnson, Jed E.; and Turley, R. Steven, "Uranium Oxide as a Highly Reflective Coating from 100-400 eV" (2004). Faculty Publications. 1059.

https://scholarsarchive.byu.edu/facpub/1059

This Peer-Reviewed Article is brought to you for free and open access by BYU ScholarsArchive. It has been accepted for inclusion in Faculty Publications by an authorized administrator of BYU ScholarsArchive. For more information, please contact ellen_amatangelo@byu.edu. 


\section{AIP Conference Proceedings}

\section{Uranium Oxide as a Highly Reflective Coating from 100-400 eV}

Richard L. Sandberg, David D. Allred, Luke J. Bissell, Jed E. Johnson, and R. Steven Turley

Citation: AIP Conf. Proc. 705, 796 (2004); doi: 10.1063/1.1757916

View online: http://dx.doi.org/10.1063/1.1757916

View Table of Contents: http://proceedings.aip.org/dbt/dbt.jsp?KEY=APCPCS\&Volume=705\&Issue=1

Published by the American Institute of Physics.

\section{Related Articles}

A cryogenic circulating advective multi-pass absorption cell

Rev. Sci. Instrum. 83, 035104 (2012)

High-performance soft $x$-ray spectromicroscopy beamline at SSRF

Rev. Sci. Instrum. 81, 103502 (2010)

A simple external resistance heating diamond anvil cell and its application for synchrotron radiation $\mathrm{x}$-ray diffraction

Rev. Sci. Instrum. 81, 053903 (2010)

SAMRAI: A novel variably polarized angle-resolved photoemission beamline in the VUV region at UVSOR-II Rev. Sci. Instrum. 81, 053104 (2010)

Calculations of synchrotron radiation emission in the transverse coherent limit

Rev. Sci. Instrum. 80, 106103 (2009)

\section{Additional information on AIP Conf. Proc.}

Journal Homepage: http://proceedings.aip.org/

Journal Information: http://proceedings.aip.org/about/about_the_proceedings

Top downloads: http://proceedings.aip.org/dbt/most_downloaded.jsp?KEY=APCPCS

Information for Authors: http://proceedings.aip.org/authors/information_for_authors

\section{ADVERTISEMENT}

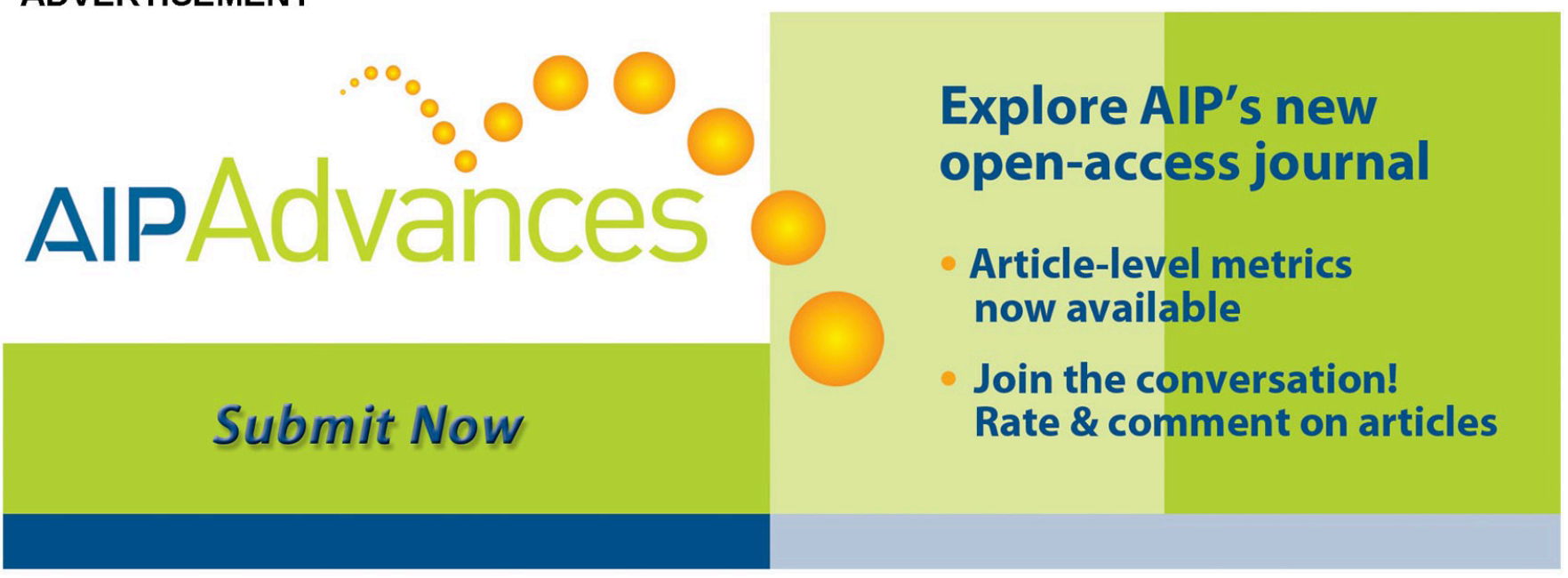




\title{
Uranium Oxide as a Highly Reflective Coating from 100-400 eV
}

\author{
Richard L. Sandberg, David D. Allred*, Luke J. Bissell, \\ Jed E. Johnson, R. Steven Turley \\ Department of Physics and Astronomy, Brigham Young University, N-283 ESC, Provo, UT USA 84602
}

\begin{abstract}
We present the measured reflectances (Beamline 6.3.2, ALS at LBNL) of naturally oxidized uranium and naturally oxidized nickel thin films from $100-460 \mathrm{eV}(2.7$ to $11.6 \mathrm{~nm})$ at 5 and 15 degrees grazing incidence. These show that uranium, as $\mathrm{UO}_{2}$, can fulfill its promise as the highest known single surface reflector for this portion of the soft x-ray region, being nearly twice as reflective as nickel in the $124-250 \mathrm{eV}(5-10 \mathrm{~nm})$ region. This is due to its large index of refraction coupled with low absorption. Nickel is commonly used in soft x-ray applications in astronomy and synchrotrons. (Its reflectance at $10^{\circ}$ exceeds that of Au and Ir for most of this range.) We prepared uranium and nickel thin films via DC-magnetron sputtering of a depleted U target and resistive heating evaporation respectively. Ambient oxidation quickly brought the $\mathrm{U}$ sample to $\mathrm{UO}_{2}$ (total thickness about $30 \mathrm{~nm}$ ). The nickel sample $(50 \mathrm{~nm})$ also acquired a thin native oxide coating $(<2 \mathrm{~nm})$. Though the density of $\mathrm{U}_{\text {in }} \mathrm{UO}_{2}$ is only half of the metal, its reflectance is high and it is relatively stable against further changes.
\end{abstract}

\section{INTRODUCTION}

This article reports the most recent results in our group's investigation of the possibility that uranium thin films can be used to increase the low-angle reflectance currently available for thin-film single-layer reflectors at about $140-250 \mathrm{eV}$ $(5-9 \mathrm{~nm})$.[1] Here we report on recent reflectance measurements from 100-460 eV (2.7 to $11.6 \mathrm{~nm}$ ) comparing naturally oxidized uranium to nickel (and nickel oxide) thin-film reflectors. Nickel was chosen for the reflectance comparison because of its wide use as a thin-film reflective coating in optical systems for the EUV and soft x-ray range.[2] Nickel's average reflectance exceeds that of gold and iridium, the other common choices for reflectors in this range. The uranium oxide and nickel samples were deposited through DC magnetron sputtering and thermal evaporation respectively at Brigham Young University. The reflectance measurements were conducted at the Advanced Light Source's Beamline 6.3.2 at the Lawrence Berkley National Laboratory. We find that the low-angle reflectance of uranium oxide surfaces exceeds that of nickel over a large wavelength range.

Uranium has a high predicted reflectance from the atomic scattering factor model due to its high density and large number of electrons (see Fig. 1). There have been several efforts to use uranium and, later, its oxides, as constituents in reflectors. First, a group at MOXTEK ${ }^{\circledast}$ investigated the preparation of U/Sc multilayer mirrors in the water window in 1993-5.[3] Second, our group used uranium in the late 1990's to prepare several near-normal-incidence U/Si EUV mirrors with high reflectance at $41 \mathrm{eV}(30.2 \mathrm{~nm})$ and low reflectance at $21 \mathrm{eV}(59.0 \mathrm{~nm})[4,5]$ for the Image spacecraft which currently orbits the Earth.[6] A third potential application of uranium for broadband, low-angle-of-incidence mirrors for the 100 to $300 \mathrm{eV}$ (4.1 to $12.4 \mathrm{~nm}$ ) range was suggest to us by Prof. Webster Cash (University of Colorado).[2] He had performed calculations in the mid 1990s indicating that uranium might produce phenomenal single-surface mirrors for x-ray astronomy, perhaps twice as reflecting as the nickel, gold or iridium mirror traditionally used for low-angle reflectance. We reported our first soft x-ray measurements of uranium films with, and without, an ultrathin carbon "barrier" top layer a year ago at the SPIE Annual Meeting of 2002.[1]

This paper reports follow up research on this earlier work. We compare the soft x-ray, low-angle reflectance of uranium covered with its native oxide $\left(\mathrm{UO}_{2}\right)$ [7] to nickel, a standard material for low-angle, soft x-ray reflectance. The nickel also has a native oxide, $\mathrm{NiO}$, but, for the same exposure to air, it is much thinner than the $\mathrm{UO}_{2}$; although, $\mathrm{NiO}$ like $\mathrm{Ni}$ is very absorbing.

*allred@byu.edu; phone 1801 422-3489; fax 1801 422-0553; http://xuv.byu.edu

CP705, Synchrotron Radiation Instrumentation: Eighth International Conference, edited by T. Warwick et al.

(C) 2004 American Institute of Physics 0-7354-0180-2/04/\$22.00

796 


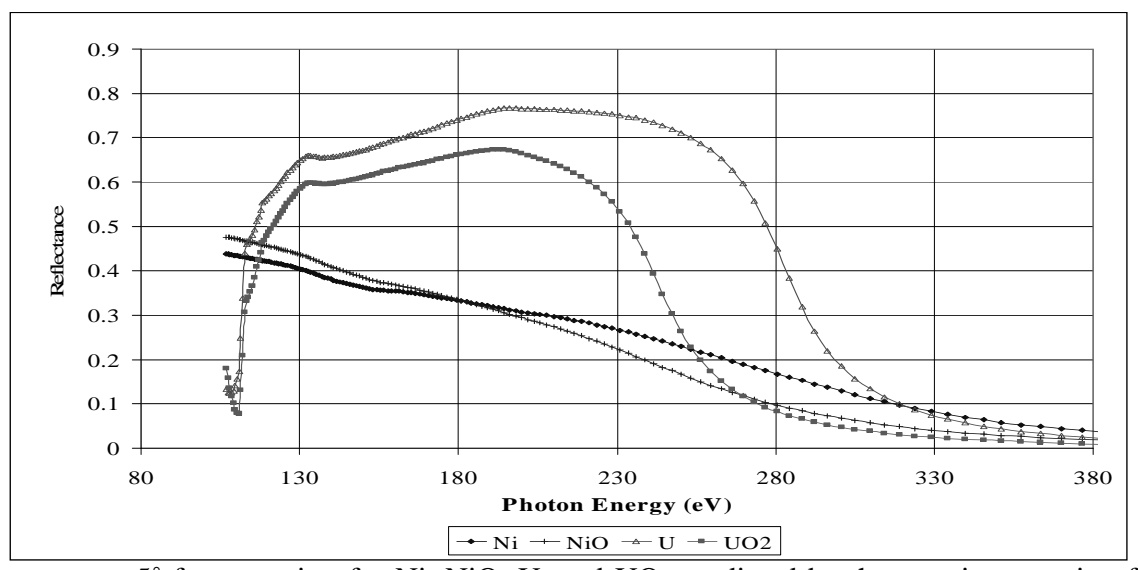

FIGURE 1. The reflectance at $5^{\circ}$ from grazing for $\mathrm{Ni}, \mathrm{NiO}, \mathrm{U}$, and $\mathrm{UO}_{2}$ predicted by the atomic scattering factor model from the CXRO website.[8]

\section{METHODOLOGY}

The uranium oxide and nickel samples were deposited on pieces of commercially available, polished silicon test wafers (100 orientation) and on pieces broken from fused quartz slides. The typical surface roughness (RMS) was examined using AFM and was $\sim 0.2 \mathrm{~nm}$ over a 100 by $100 \mathrm{~nm}$ area. The DC magnetron sputtering and evaporation systems are located in the Department of Physics and Astronomy at Brigham Young University and the processes followed are similar as those described in previous works by the BYU EUV group.[1,4,5,6,7,9,10]

The uranium samples were sputter deposited in a cryopumped (CryoTorr 8) chamber. The uranium sputter targets were depleted uranium metal (less than $0.2 \% \mathrm{U}-235$ ). Radiation from the films is low. A Geiger counter cannot detect the radiation from the ultrathin uranium samples above background radiation. Prior to this study, studies of the oxidation rates of uranium thin films have been conducted.[7] When we refer to the reflectance and other properties of the uranium oxide film used in the study, it should be understood that this means the most abundant natural oxide of uranium, $\mathrm{UO}_{2}$. Our nickel films were prepared by evaporating $\mathrm{Ni}$ wire from a resistively heated tungsten boat (RD Mathis Co.) in a large, cryopumped, stainless steel "bell jar" coater. The base pressure of the system was $3.2 \times 10^{-4} \mathrm{~Pa}\left(2.4 \times 10^{-6}\right.$ torr). Quartz crystal monitors were used to measure the sputter or evaporation rates respectively. Two samples were deposited and are referred to as $\mathrm{NiO}$ on $\mathrm{Ni}$ and $\mathrm{Ni}$ on quartz deposited on silicon and quartz respectively.

Thin-film interference of scattered $\mathrm{x}$ rays was used to determine the thickness of our deposited thin films. Using a Scintag $^{\circledR}$ X-ray diffractometer (XRD), we measured the low-angle reflectance at $\mathrm{Cu}-\mathrm{K} \alpha$, giving particular interest to interference maxima and minima. Modeling the XRD data using Scintag software gives the approximate thickness of our samples. Subsequently, we used IMD to model our layers. ${ }^{11}$ By adjusting the thickness of the modeled layer, the diffraction peaks of the model and the measured XRD can be matched, giving the layer thickness. For nickel, this thickness was $49.7 \pm 0.5$ $\mathrm{nm}$. For the uranium oxide sample this was $31.8 \pm 0.5 \mathrm{~nm}$.

The reflectance measurements were conducted at the Advanced Light Source (ALS) at Lawrence Berkley National Laboratory at the University of California-Berkley on Beamline 6.3.2. The process of normalization to extract reflectances are described in more detail along with further details on Beamline 6.3.2 at the CXRO webpage and can be found in Underwood.[8,12,13] Different filters corresponding to these gratings select which wavelength ranges are desired. However, the filters do not perfectly suppress other orders than the desired order, so the source is not perfectly monochromatic. This polychromaticity can cause measured reflectances of overlapping wavelength regions to differ slightly as can be seen in Fig. 2 and Fig. 3 at 146, 188, and $276 \mathrm{eV}$. Also, some of the measurements on the nickel samples were made after the sample had been removed and then returned to the reflectometer. We attribute the inconsistencies seen in our measured data to these two factors.

\section{DATA}

Here we present the reflectance data measured at ALS Beamline 6.3.2 on June 13-15, 2003. We separate the data presented here into two categories depending upon the grazing incidence angle at $5^{\circ}$ or $15^{\circ}$. The graphs are split up into the corresponding wavelength scans available at Beamline 6.3.2. Each chart has three lines. The curves with squares, circles and triangles correspond to the measured reflectance of $\mathrm{UO}_{\mathrm{x}}, \mathrm{NiO}$ on $\mathrm{Ni}$, and $\mathrm{Ni}$ on Quartz respectively. 


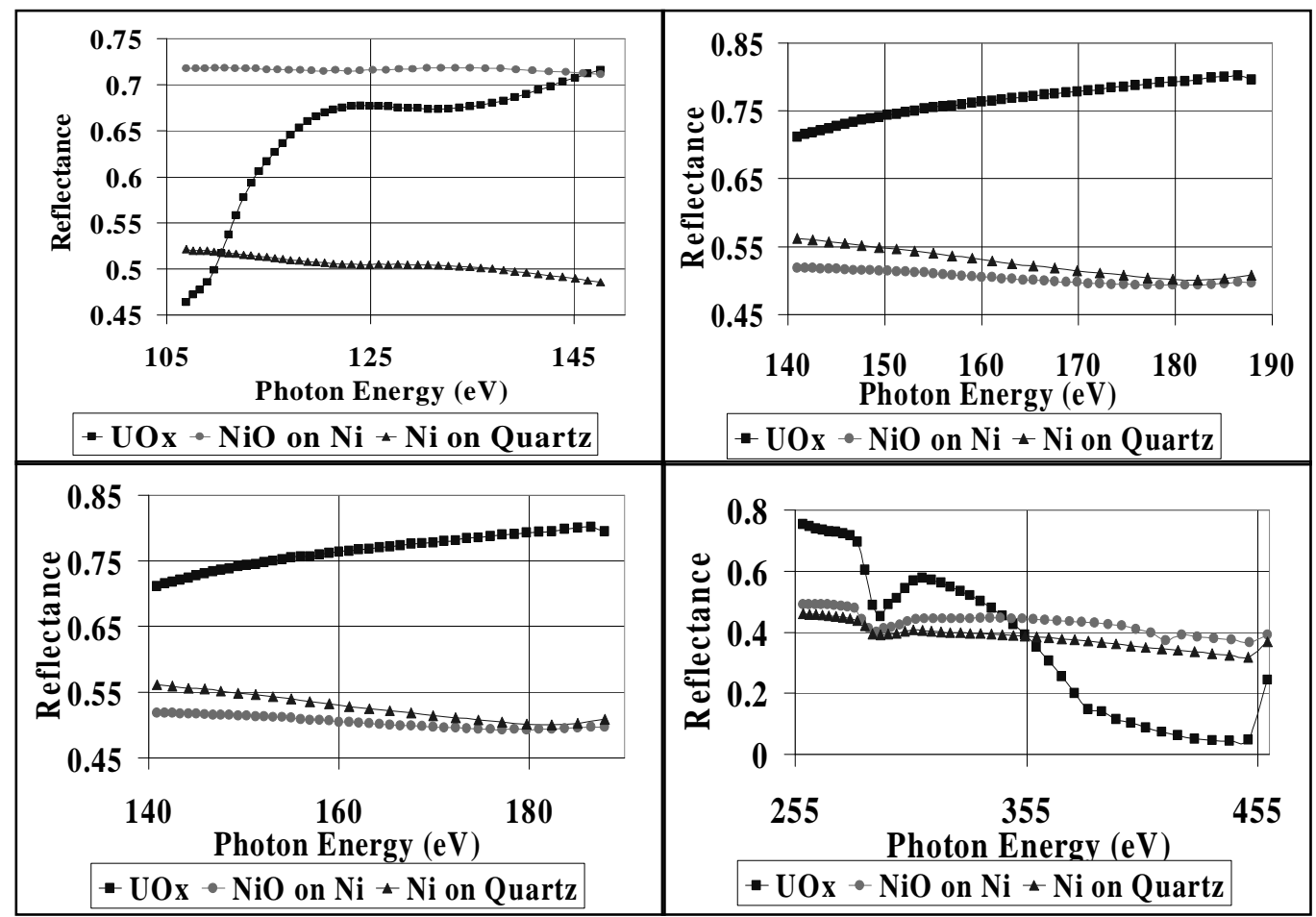

FIGURE 2. Measured reflectance of $\mathrm{UOx}, \mathrm{NiO}$ on $\mathrm{Ni}$, and $\mathrm{Ni}$ on quartz at 5 degrees from $106-460 \mathrm{eV}$.

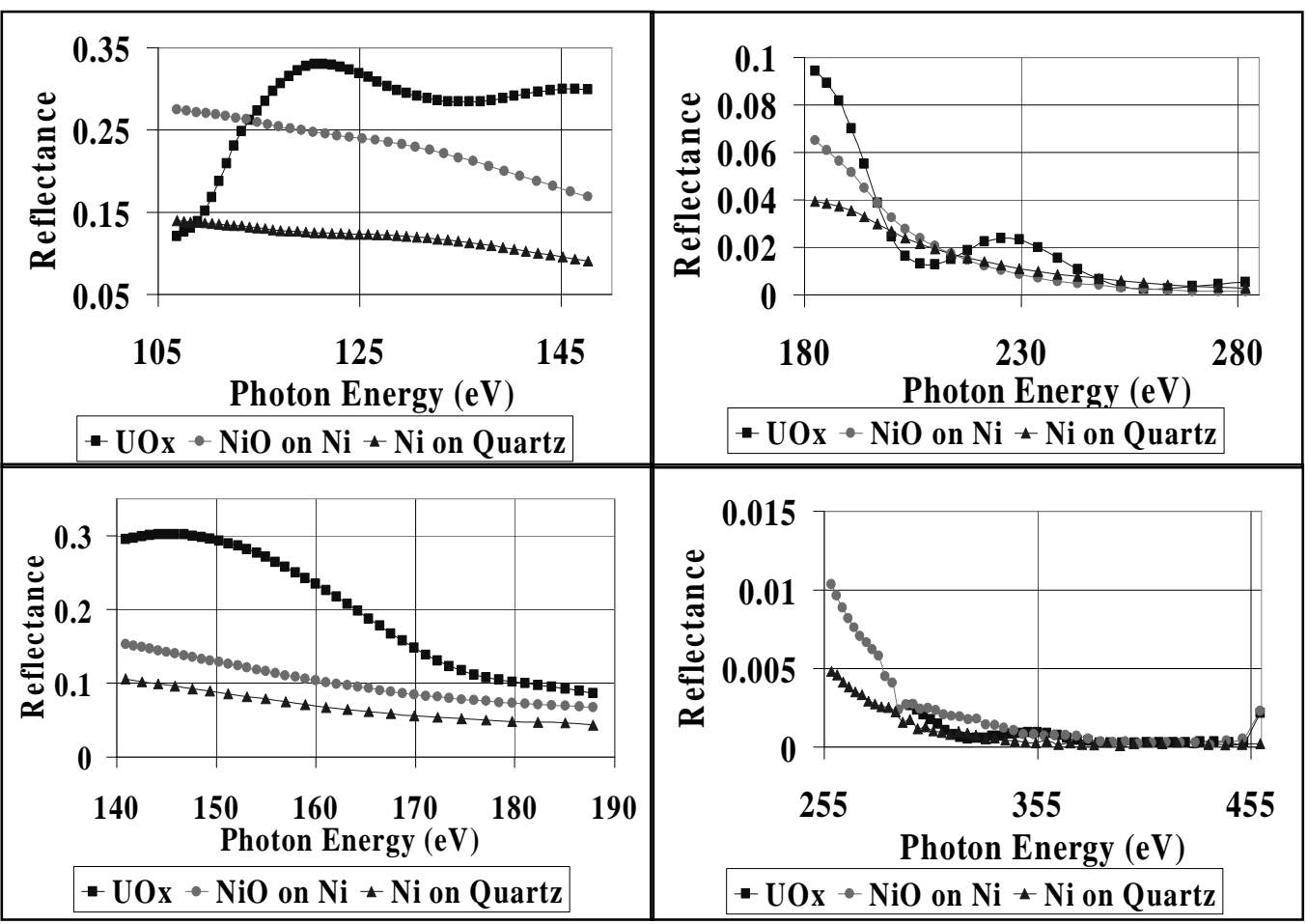

FIGURE 3. Reflectance at 15 degrees of $\mathrm{UO} 2, \mathrm{NiO}$ on $\mathrm{Ni}$, and $\mathrm{Ni}$ on Quartz from 106-460 eV. 
As shown in Fig. 2, at $5^{\circ}$ uranium oxide reflects more than nickel from 146 to $345 \mathrm{eV}$ (3.6 to $8.5 \mathrm{~nm}$ ). At this lower grazing incidence angle, uranium oxide has a maximum reflectance of $80 \%$ from 188 to $240 \mathrm{eV}$ (5.2 to $6.6 \mathrm{~nm}$ ) as shown in Fig. 2. This value is $20-40 \%$ greater than the reflectance of nickel here. Notice in Fig. 2 the dip in reflectance of all three graphs at about $285 \mathrm{eV}(4.3 \mathrm{~nm})$. This may correspond to the absorption edge of carbon near $284 \mathrm{eV}$ which may be due to thin organic layers that form on surfaces when they are exposed to ambient air. In Fig. 2, we also notice two interesting features of uranium oxide. First, we notice a feature similar to an interference minimum at about $135 \mathrm{eV}(\sim 9.4 \mathrm{~nm})$ which we will see appear more strongly at higher angles. Second, we notice an apparent absorption edge at $100 \mathrm{eV}(11.4 \mathrm{~nm})$. At $15^{\circ}$, uranium oxide reflects more than nickel from 114 to $196 \mathrm{eV}(6.3 \mathrm{~nm}$ to $10.9 \mathrm{~nm})$. As seen in Fig. 3, uranium oxide reaches a maximum reflectance of $33 \%$ at $120 \mathrm{eV}(10.3 \mathrm{~nm})$. This wavelength also corresponds to a strong interference fringe. The existence and significance of this fringe is discussed elsewhere.[10]

\section{CONCLUSIONS}

Naturally oxidized uranium thin-film reflectors were found to be more reflective than nickel or nickel oxide on nickel over a large range of angles and wavelengths as predicted by the ASF model. Specifically, uranium oxide reflects more than nickel at $5^{\circ}$ grazing incidence from 146 to $345 \mathrm{eV}(3.6$ to $8.5 \mathrm{~nm})$ and at $15^{\circ}$ grazing incidence from 114 to $196 \mathrm{eV}$ (6.3 nm to $10.9 \mathrm{~nm}$ ). The maximum reflectance from $100-460 \mathrm{eV}$ of this uranium oxide was measured to be an impressive $80 \%$ at $5^{\circ}$ and $33 \%$ at $15^{\circ}$ grazing incidence. We therefore recommend that uranium oxide-based mirror coatings should be developed and implemented for future projects where broadband, low angle, soft x-ray mirrors are required.

\section{ACKNOWLEDGEMENTS}

We are grateful to Hollilyn Drury and Megan Rowberry for aiding in sputtering the uranium film studied. We also acknowledge grateful the financial contributions of V. Dean and Alice J. Allred and Marathon Oil Company (US Steel) for gifts to BYU for thin-film research. We are grateful to Eric Gullikson and Andy Aquila at ALS Beamline 6.3.2 at LBNL for their help in data interpretation, reduction, and analysis.

\section{REFERENCES}

[1] D. D. Allred et al., "Highly Reflective Uranium Mirrors for Astrophysics Applications," in X-ray Mirrors, Crystals and Multilayers, Andreas K. Freund, Albert T. Macrander, Tetsuya Ishikawa, and James. T. Wood, Editors, Proc. SPIE 4782, pp. 212223, SPIE, Bellingham, WA, 2002.

[2] Webster Cash, Private Communication.

[3] Hans Pew, Private Communication.

[4] D. D. Allred, R. S. Turley, and M. B. Squires, "Dual-function EUV multilayer mirrors for the IMAGE mission," in EUV, $X$-Ray and Neutron Optics, Carolyn A. Macdonald, Kenneth A. Goldberg, Juan R. Maldonado, H. Heather Chen-Mayer, and Stephen P. Vernon, Editors, Proceedings of SPIE 3767, pp.280-287, SPIE, Bellingham, WA, 1999.

[5] Matthew B. Squires. "The EUV Optical Constants of Sputtered U and a-Si," Honors Thesis, Brigham Young University, Provo, UT, April 1999. http://volta.byu.edu

[6] B. R. Sandel et al., Space Science Reviews 91, pp. 197-242 (2000).

[7] David Oliphant (oliphantd@ @yui.edu), “Characterization of Uranium, Uranium Oxide and Silicon Multilayer Films,” Masters thesis, Dept. of Physics and Astronomy, BYU, Provo, UT 2000. Contact the BYU HBL library at http://www.lib.byu.edu/hbll/ or in partial form at http://www.byui.edu/Ricks/employee/oliphantd/.

[8] http://www-cxro.lbl.gov/optical constants/mirror2.html, June-July, 2003, using the option "thick mirrors."

[9] Shannon Lunt, "Determining the Indices of Refraction of Reactively Sputtered Uranium Dioxide Thing Films from 46 to 584 Angstroms," Masters Thesis, Dept. of Physics and Astronomy, BYU, Provo, UT 2002. Contact the BYU HBL library at http://www.lib.byu.edu/hbll/

[10] R. L. Sandberg et al., "A Comparison of Uranium Oxide and Nickel as Single-layer Reflectors from 2.7 to 11.6 Nanometers," in Advances in Mirror Technology for X-Ray, EUV Lithography, Laser, and Other Applications, Ali M. Khounsary, Udo Dinger, Kazuya Ota, Editors, Proc. SPIE 5193, SPIE, Bellingham, WA, 2003.

[11] Program for EUV and X-ray reflectance calculations, courtesy of Prof. David L. Windt: windt@astro.columbia.edu. http://cletus.phys.columbia.edu/windt/idl.

[12] http://www-cxro.lbl.gov/als6.3.2/, July, 2003 or contact Eric Gullikson from the webpage for additional questions.

[13] J.H. Underwood et al. Rev. Sci. Instrum., 67 (9), pp. 1-5 (1996). 